Erratum

\title{
The Role of Standpoint in Justice Theory
}

\section{NANCY S. JECKER}

Department of Medical History and Ethics, University of Washington, Box 357120, Seattle,WA98195-7120,USA; e-mail:nsjecker@u.washington.edu

\section{Erratum to: The Journal of Value Inquiry DOI 10.1007/s10790-007-9091-7}

During the proof procedure of the above mentioned article the first paragraph was erroneously omitted.

Philosophers have a long history of thinking about justice from the standpoint of the ideally just individual. In this paper we explore the limitations of such an approach and consider an alternative. The alternative encompasses both empirical and analytical claims. The empirical claim starts with the standpoint of injustice and those who suffer it, and develops the idea of an empirically based sense of injustice. A sense of injustice helps us to notice things we might otherwise overlook. The analytical claim asserts that the standpoint of injustice is necessary for a complete picture of justice. Using specific examples, it is argued that certain aspects of justice can be understood only from an injustice standpoint. After considering a series of objections, we are led to conclude that the requirements of empirical and conceptual adequacy are interrelated. By supplementing ideal justice with the perspective of injustice, we better meet requirements of both empirical and conceptual adequacy.

The online version of the original article can be found under doi: 10.1007/s10790-007-9091-7. 